\title{
Some estimates of the Baltic deep-water transport through the Stolpe trench
}

\author{
By K. BORENÄS ${ }^{1 *}$, R. HIETALA ${ }^{2}$, J. LAANEARU ${ }^{3}$ and P. LUNDBERG ${ }^{4},{ }^{1}$ SMHI, Nya Varvet 31, \\ SE-42671 Västra Frölunda, Sweden and Dept. of Oceanography, Earth Sciences Centre, Göteborg University, Box \\ 460, SE-405 30 Göteborg, Sweden; ${ }^{2}$ Finnish Institute of Marine Research, P.O. Box 33, FIN-00931 Helsinki, Finland; \\ ${ }^{3}$ Department of Mechanics, Tallinn University of Technology, Ehitajate tee 5, EE-19086 Tallinn, Estonia; ${ }^{4}$ Department \\ of Meteorology/Physical Oceanography, Stockholm University, SE-10691 Stockholm, Sweden
}

(Manuscript received 4 August 2005; in final form 17 November 2006)

\begin{abstract}
The subsurface flow of high-saline water masses from the Bornholm Basin through the Stolpe Channel plays an important role for the renewal of the Baltic Central Basin deep waters. In order to determine whether rotating $1 \frac{1 / 2}{2}$-layer hydraulic theory is an appropriate tool for describing this process, maximal-transport estimates based on climatological data from the Bornholm and Gdansk Basins have been established. These were found to deviate considerably from observational realities, and hence similar hydraulic considerations were also applied to more-or-less synoptic field data from a Finnish field campaign carried through in the mid-1980s. Also in this case significant differences were found between calculated transport capacity and observations. Since it furthermore was demonstrated that the characteristics of the observed crosschannel hydrographic structure could be explained using a frictional-balance model of the deep-water flow, it has been concluded that a hydraulic framework, although providing an upper bound of the transport, is of limited use when dealing with the Stolpe-Channel overflow. Although it cannot be excluded that the inflow is inviscid, but submaximal, it is more likely that the transport is governed by the combined effects of friction and wind forcing.
\end{abstract}

\section{Introduction}

The Baltic is a large semi-enclosed sea (see Fig. 1) characterized by a considerable freshwater excess (Omstedt et al., 1997) due to its large drainage basin. It is thus strongly stratified, with a brackish surface layer superimposed on a deep-water layer of higher salinity and density. These deeper water masses are periodically renewed by high-saline inflows from the Kattegat and Skagerrak through the Danish Straits (Schinke and Matthäus, 1998). After having passed the Arkona basin the deep water debouches through the Bornholm Channel (Petrén and Walin, 1976) into the Bornholm Basin, subsequently making its way to the Baltic Proper via the Stolpe (Slupsk) Channel. This latter passage connecting the Bornholm and Gdansk basins thus plays a significant role for the deep-water renewal in the main body of the Baltic.

The Baltic deep-water flows through lateral constrictions and/or over sills have been subjected to considerable scientific inquiry, since what takes place at these choke-points to a large

\footnotetext{
*Corresponding author.

e-mail: karin.borenas@smhi.se

DOI: $10.1111 / \mathrm{j} .1600-0870.2006 .00221 . x$
}

degree controls the biogeochemical state of the deep basins. A crucial question is if the transports can be described in inviscid terms, for example, within a hydraulic framework, or whether a full understanding of these overflows requires that friction be taken into account. This problem is as yet not resolved; for example, Lundberg (1983) as well as Gidhagen and Håkansson (1992) dealt with the Bornholm-Channel overflow within a framework invoking the effects of friction. Following the pronounced deep-water inflow to the Baltic during the winter of 1993 several investigators, however, provided descriptions of the process couched in inviscid, hydraulic terms. Liljebladh and Stigebrandt (1996) thus presented calculations of this overflow event across the Bornholm sill based on the assumption that the deep-water flow was characterized by zero potential vorticity, whereas Laanearu and Lundberg (2000) extended the analysis by suggesting the use of finite potential vorticity in the hydraulic analysis.

As regards the deep-water transport through the Stolpe Channel, comparatively little systematic discussion of this overflow and its dynamics has been undertaken. Pedersen (1977), although to some extent dealing with the magnitude of the overflow, primarily focused his analysis on the entrainment processes affecting the deep water on its way towards the Stolpe Channel. 
Fig. 1. Map of the southern Baltic showing the standard ICES hydrographic stations (BY5 in the Bornholm Basin and BCS III-10 in the Gdansk Basin) used for establishing climatological results. Included are also the hydrographic sections worked by the Finnish Institute of Marine Research in July/August 1986.

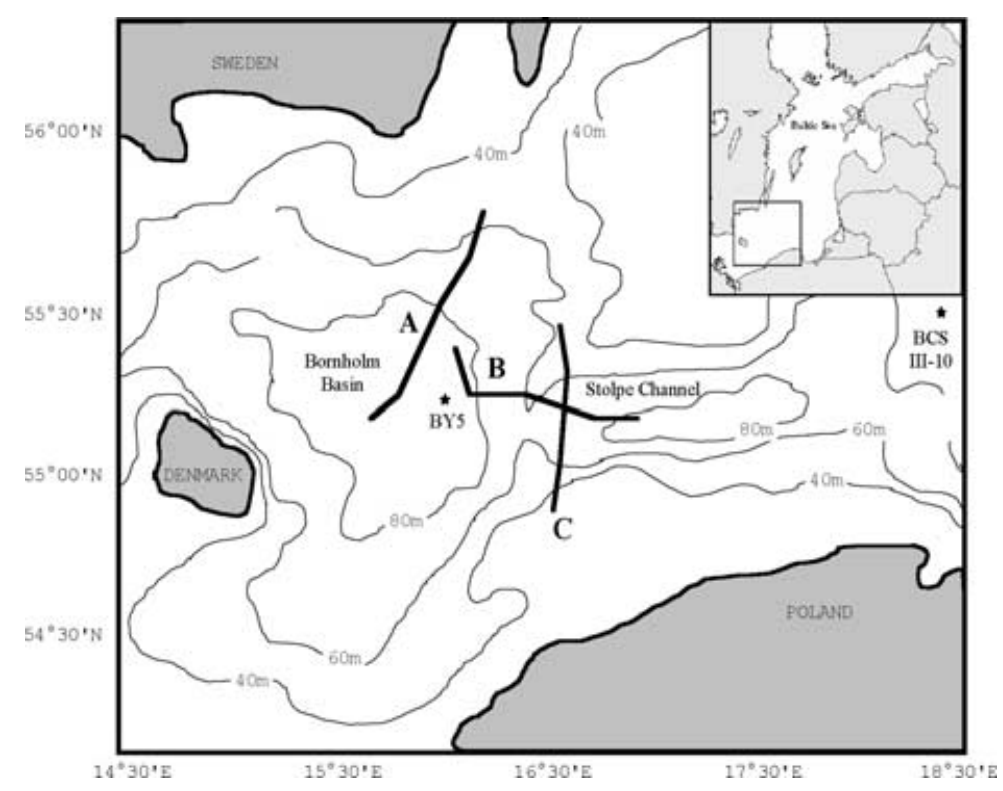

Rydberg (1980) attempted to reconcile an evidently geostrophically balanced deep-water flow (as manifested by the observed strong cross-channel slope of the density surfaces) with the formalism of non-rotating hydraulics. A numerical investigation of wind-forced water exchange between the Baltic deep basins (Krauss and Brügge, 1991) is of particular interest in the present context. This study explicitly dealt with the Stolpe Channel and showed that northerly and easterly winds over the southern Baltic give rise to significant deep-water fluxes from the Bornholm to the Gdansk Basin. The most recent model studies of the Baltic, comprising results of relevance for the present investigation, have been reported by Meier and co-workers (Meier and Kauker, 2003; Meier et al., 2003). A connected-reservoir model for the deep water of the Baltic proper was formulated by Kõuts and Omstedt (1993), who based their work on hydrographic data from 1970 to 1990 . The main focus of this study was on the deep-water fluxes through various choke points (including Stolpe Channel) and on the associated entrainment processes.

During the mid-1980s field campaigns in the Bornholm BasinStolpe Channel area were carried out by the R/V Aranda, operated by the Finnish Institute of Marine Research (Mälkki, 1988). These surveys were primarily based on hydrographic casts, but a number of recording current-meter deployments was also carried out. As an example of the results obtained, Fig. 2 shows the hydrographic conditions (expressed in terms of the isohalines) found over the threshold section at the western end of the Stolpe Channel on July 26, 1986. Since in the Baltic TS-regime the density is predominantly determined by the salinity, it is recognized that on this occasion the isopycnal distribution was consonant with a geostrophically balanced deep-water flow in the downchannel direction towards the Gdansk Basin. In this context it must also be noted that a recent field study of a medium-sized inflow event to the Baltic has been reported by Piechura and

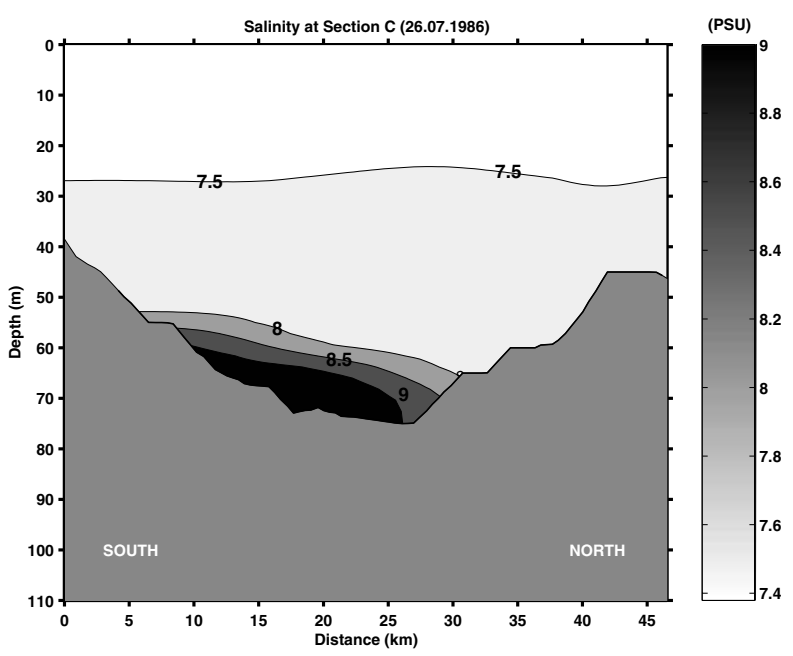

Fig. 2. Salinity section across the Stolpe Channel threshold area (section C in Fig. 1) taken on July 27, 1986. The slope of the isohalines indicates a geostrophically balanced deep-water flow in the eastward direction.

Beszczyńska-Möller (2003), who carried out altogether six exceptionally detailed surveys of the Bornholm Basin and Stolpe Channel from December 2002 to August 2003.

In the present study we shall take a fresh look at the deepwater flow through the Stolpe Channel. Initially the analysis will be focused on long-term hydrographic data sets from the Gdansk and Bornholm basins, this in order to determine the parametric regime which in a climatological sense can be said to characterize the overflow. Using these results, maximal-transport estimates for various representations of the Stolpe-channel topography will hereafter be established on the basis of rotating hydraulic theory, this since previous experience from the Baltic 
(Laanearu et al., 2000; Laanearu and Lundberg, 2000) indicates that the deep-water flow may be described within this framework. The advantage of applying hydraulic theory is that the maximum flow rate is uniquely determined by a limited number of upstream parameters and the geometrical configuration of the sill. The analyses are carried through for the potential vorticity prescribed as zero as well as a constant finite value. Additionally, the hydrographic conditions encountered during some of the above-mentioned R/V Aranda field surveys will be taken into account, in particular for a sensitivity analysis of the hydraulic maximal-transport estimates. These observational results also constitute the basis for a general discussion of how appropriate it is to apply a hydraulic framework to describe the deep-water flow through the Stolpe Channel, a process which is not ideal as regards fulfilling the criteria for the validity of a $1 \frac{1}{2}$-layer hydraulic approach. Wind forcing can, for example, give rise to considerable deep-water transports between the Bornholm and Gdansk basins (Krauss and Brügge, 1991). Friction may also play an important role, and it is demonstrated that the field observations are compatible with a frictionally balanced deep-water flow from the Bornholm to the Gdansk Basin. The investigation is concluded by an overview of the prospects for future work concerning the deep-water flows in the Baltic.

\section{Bifurcation-depth analysis}

We initiate our discussion of the deep-water flow through the Stolpe Channel by applying rotating hydraulic theory (Pratt and Lundberg, 1991) to a $1 \frac{1}{2}$-layer system, that is, an active lower layer of density $\rho+\Delta \rho$ and a deep, quiescent upper layer of density $\rho$.
Whitehead $(1989,1998)$ suggested a novel use of hydrographic data sets to determine not only the density difference $\Delta \rho$ characterizing the long-term deep-water exchange between two adjacent ocean basins, but also the upstream-reservoir level, $\eta_{\infty}$, of the interface separating the two idealized layers. Since precise knowledge of these quantities plays a crucial role for hydraulic analyses, care must be taken when specifying them.

The Baltic is characterized by much smaller scales than the ocean basins originally considered by Whitehead. From an oceanographic standpoint it is, nevertheless, an advantageous region for working in, since regular hydrographic surveys have been undertaken over a very long period of time. To estimate the deep-water flow through the Stolpe Channel we shall make use of standard hydrographic data from an upstream location in the Bornholm Basin (ICES station BY5 at $58^{\circ} 15^{\prime} \mathrm{N}, 15^{\circ} 59^{\prime} \mathrm{E}$ ) as well as from a down-stream site in the Gdansk Basin (standard station BCS III- 10 at $55^{\circ} 33^{\prime} \mathrm{N}, 18^{\circ} 24^{\prime} \mathrm{E}$ ) when carrying through the Whitehead procedure, see Fig. 1.

The high-quality data span the period 1957-1999, with a total of around 550 water-bottle or CTD casts for BY5 and 400 for BCS III-10. The measurements from both stations are summarized in Figs. 3 and 4, which for 10-m depth intervals show the resulting averages and standard deviations of the vertical salinity and temperature distributions. It is immediately striking how stable the salinity profiles are in the near-surface region, whereas the corresponding temperatures clearly demonstrate the effects of the pronounced annual atmospheric heating and cooling cycle. At deeper levels the salinities show larger variations due to intermittent deep-water inflows, while the temperatures tend to be more stable than in the surface layer. Since, as previously underlined, salinity effects dominate the equation of state in the
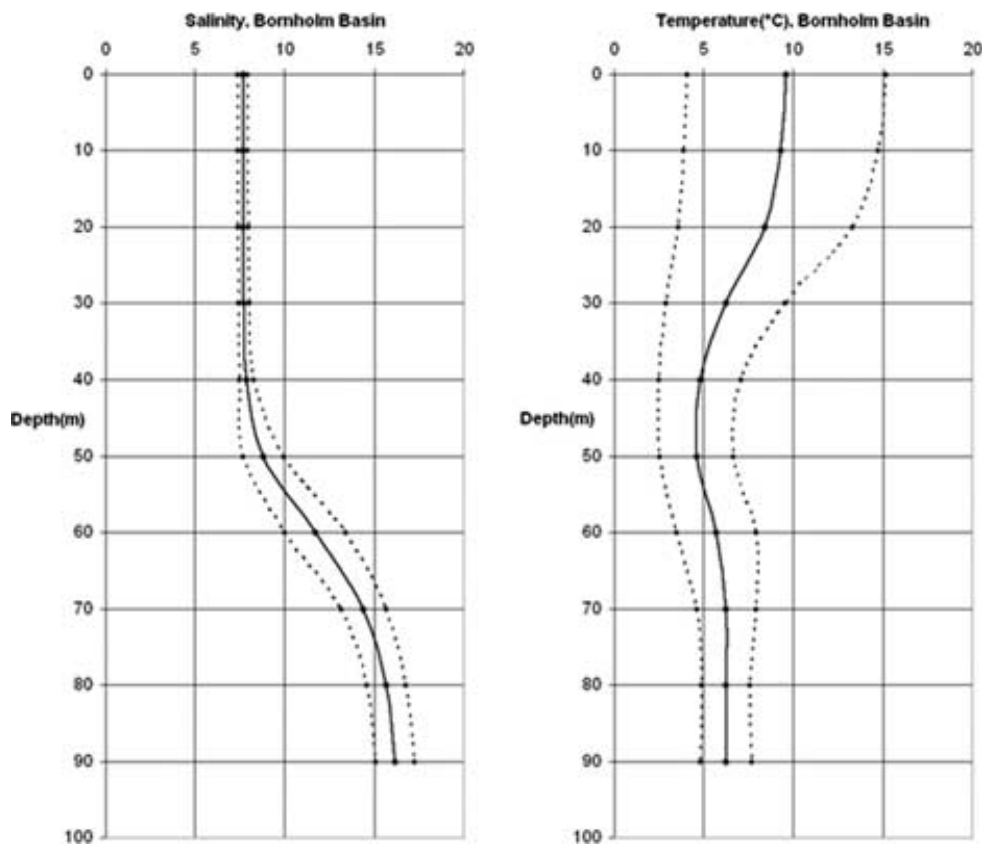

Fig. 3. Climatological averages and standard deviations of the observed salinity and temperature profiles at station BY5 in the Bornholm Basin 1957-1999. 
Fig. 4. Climatological averages and standard deviations of the observed salinity and temperature profiles at station BCS III-10 in the Gdansk Basin 1957-1999.

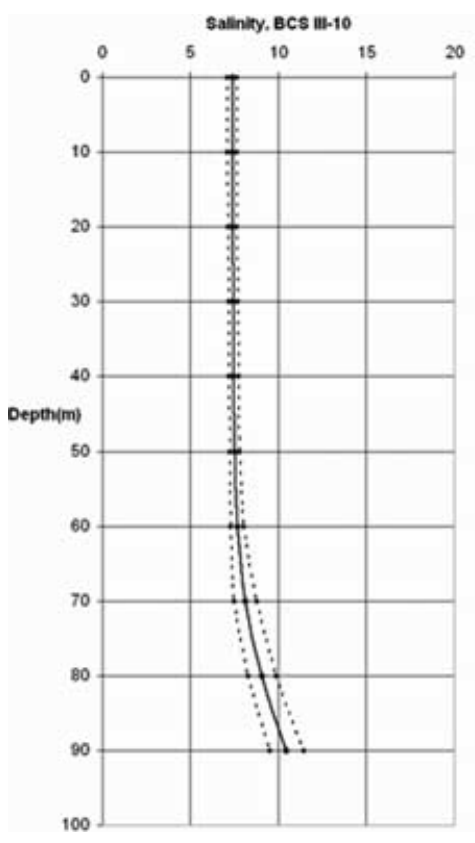

TS-regime prevailing in the Baltic, the associated density profiles, as shown for both of the basins in Fig. 5, demonstrate a behaviour similar to that characterizing the salinity.

Applying the procedure due to Whitehead $(1989,1998)$ to the results shown in Fig. 5, it is recognized that the 'climatological' bifurcation (i.e. where the density curves separate from one another) takes place for $S \approx 7.9$ at a depth of around $40 \mathrm{~m}$ from the sea surface. Since the sill has a maximum depth of $63 \mathrm{~m}$, the upstream height of the interface can be estimated as $\eta_{\infty}=23 \mathrm{~m}$. Analogously $\Delta \rho$ is determined from the greatest density difference between the two stations at or above sill depth, and was in the present case found to be $\Delta \rho \approx 3 \mathrm{~kg} \mathrm{~m}^{-3}$ which in turn yields a reduced gravity $g^{\prime}=g \Delta \rho / \rho \approx 2.94 \times 10^{-2} \mathrm{~ms}^{-2}$. These estimates will serve as a basis for the forthcoming investigation.

\section{Maximal-transport estimates}

When carrying through an investigation of a deep-water flow based on $1 \frac{1}{2}$-layer rotating hydraulics, a number of prerequisites must be fulfilled in order for the analysis to be valid. Hence it is essential that the density structure be of a two-layer character with a deep and quiescent upper layer. Furthermore, it is necessary that the flow not only changes slowly in the alongchannel direction but also that it is stationary and can be dealt with as inviscid. (As to be further discussed and evaluated, none of these conditions can be regarded as strictly satisfied for the Stolpe-Channel deep-water flow.)

Within this framework, the most straightforward hydraulic maximal-transport estimates are those obtained using the classical Whitehead et al. (1974) formalism for flow of approximately zero potential vorticity through a box-like channel, that is, a

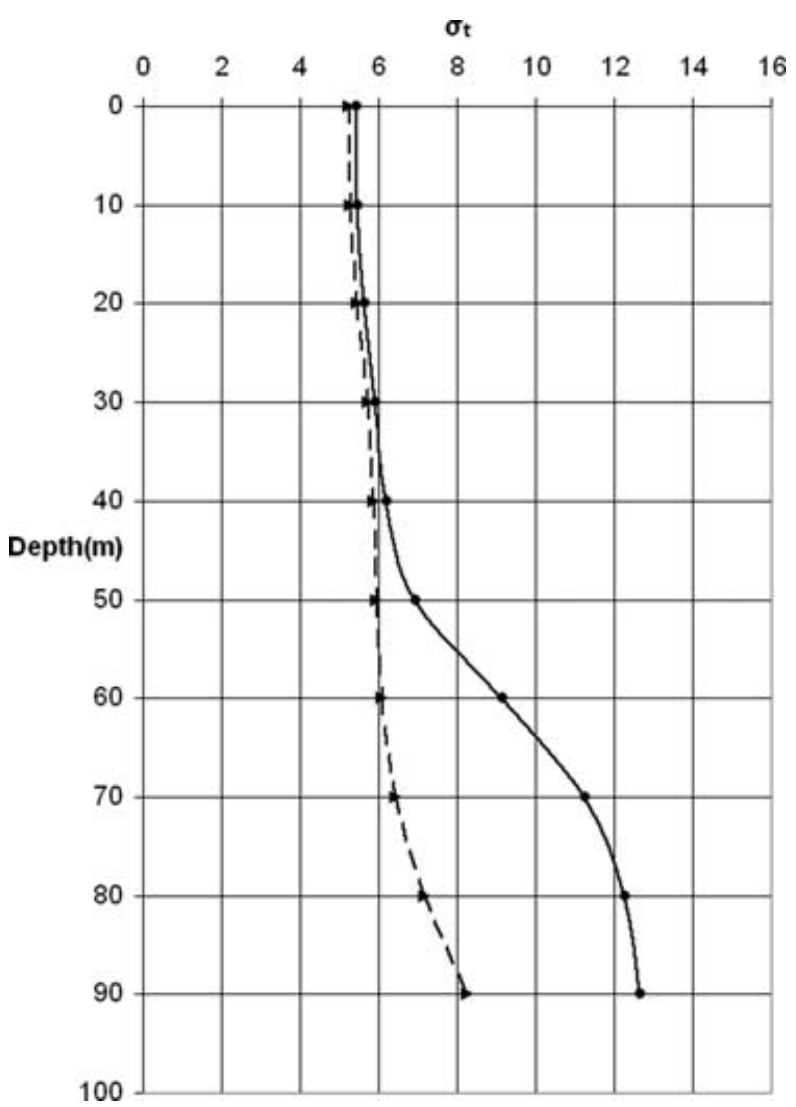

Fig. 5. Climatological averages of the density stratification at stations BY-5 (solid line) and BCS III-10 (dashed line) 1957-1999. The two curves are seen to bifurcate at a depth of around $40 \mathrm{~m}$ (corresponding to $S \approx 7.9$, cf. Figs. 3 and 4 ). 
passage with vertical walls and a horizontal bottom. The Stolpe Channel threshold section (cf. Fig. 2) is comparatively broad, with around $30 \mathrm{~km}$ between the 50-m isobaths. This length-scale well exceeds the internal Rossby radius, and hence the pertinent formula for the maximal transport is

$Q_{\max }=g^{\prime} \eta_{\infty}^{2} / 2 f$.

3.

Evaluating this expression for $f=1.19 \times 10^{-4} \mathrm{~s}^{-1}$, and the previously introduced values of $g^{\prime}$ and $\eta_{\infty}$, results in $Q_{\max } \approx$ $65300 \mathrm{~m}^{3} \mathrm{~s}^{-1}$. This upper bound of the transport, based on the average climatological conditions encountered in the Bornholm and Gdansk basins over the past $40-\mathrm{yr}$ period, is larger than most previous estimates and is in reality only attained during extreme inflow events such as that which took place during the winter of 1993, cf. Liljebladh and Stigebrandt (1996). In this context it may, as a point of reference, be noted that the classical mass-balance estimate (Knudsen, 1900) of the deep-water inflow from the Kattegat to the Baltic $\left(450 \mathrm{~km}^{3} \mathrm{yr}^{-1}\right)$ corresponds to $14000 \mathrm{~m}^{3} \mathrm{~s}^{-1}$. However, considerable entrainment of Baltic surface water takes place underway as noted by Pedersen (1977), who estimated the Stolpe Channel deep-water transport of salinities above 8 to range from 23000 to $54000 \mathrm{~m}^{3} \mathrm{~s}^{-1}$. A recent numerical study (Meier and Kauker, 2003), encompassing the period 1902-1988, shows that the long-term average of this deep-water transport may have a lower bound of around 30000 $\mathrm{m}^{3} \mathrm{~s}^{-1}$.

Since the severe idealization represented by the box-like topography may have played a role for the somewhat unrealistic long-term result derived above, the maximal-transport formula for flow of zero potential vorticity through a parabolic channel (Borenäs and Lundberg, 1988) has also been applied, viz.

$Q_{\max }=\eta_{\infty}^{2}\left(3 g^{\prime} / 2 \alpha\right)^{1 / 2}\left(2+f^{2} / g^{\prime} \alpha\right)$,

where the best parabolic fit (in a least-squares sense) of the bathymetry obtained for $\alpha=3.5 \times 10^{-8} \mathrm{~m}^{-1}$ is shown in Fig. 6 . Based on the same 'forcing' $\Delta \rho / \rho$ and $\eta_{\infty}$ as employed above, direct use of this formula yields a considerably lower transport estimate $Q_{\max } \approx 37700 \mathrm{~m}^{3} \mathrm{~s}^{-1}$. When the resulting flow structure is examined more closely, it is recognized that, due to width of the Stolpe trench exceeding the internal Rossby radius, the flow does not have a unidirectional velocity distribution but manifests a pronounced return-flow zone on the southern side of the channel, cf. Borenäs and Lundberg (1988). Killworth (1994) noted that in cases like these maximal flow is obtained by replacing the zone of reverse flow with a stagnant region, cf. Borenäs and Nikolopoulos (2000). When this is carried out for the zero PV case presently under consideration, $Q_{\max }$ is found to be $54000 \mathrm{~m}^{3} \mathrm{~s}^{-1}$.

Examining the Bornholm-Basin and Stolpe-Channel bathymetry (Fig. 1) it is, however, seen that the upstream reservoir is comparatively shallow. Since the channel width furthermore exceeds the internal Rossby radius of deformation, this to a considerable extent invalidates the zero potential

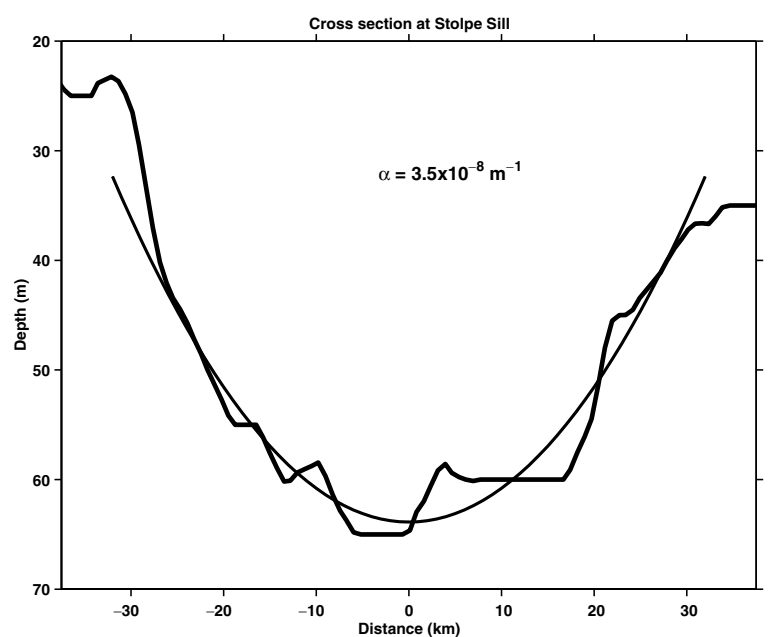

Fig. 6. Best parabolic fit to the observed cross-channel topography at section C in the Stolpe Channel sill area, cf. Fig. 1.

vorticity assumption. We shall thus next estimate the maximal Stolpe-Channel deep-water overflow using the general framework of a finite but constant PV flow through a rotating channel of parabolic cross-section (Borenäs and Lundberg, 1986). Directly applying this formalism in the limiting cases when the upstream reservoir transports are confined to left- and rightbank boundary layers yields $Q_{\max }=49000$ and $98000 \mathrm{~m}^{3} \mathrm{~s}^{-1}$, respectively. Since the latter of these transports is unrealistically large, we in what follows focus on the case of 'left-bank' upstream flow. Since also this case exhibits a return flow at the threshold a similar procedure as above is applied. (For specific details of the analysis when the zone of return flow is replaced by a stagnant region, the reader is directed to Appendix A.) The calculations were also in this case carried out for the previously introduced climatological values of $g^{\prime}$ and $\eta_{\infty}$. The upstream reservoir depth was prescribed as $90 \mathrm{~m}$ and the potential depth (Borenäs and Pratt, 1994) was identified with the lower-layer thickness, viz. $D_{\infty}=50 \mathrm{~m}$. The results are presented in Fig. 7 showing the transport as a function of the

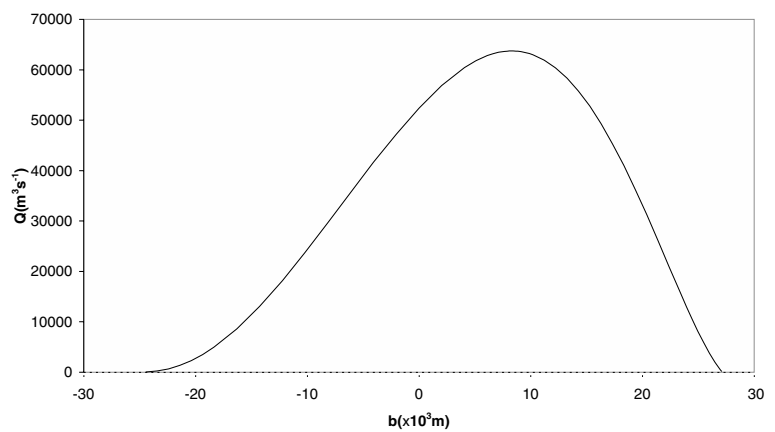

Fig. 7. Calculated deep-water transport through the Stolpe Channel as a function of the location of the streamline separating the stagnant zone on the southern side of the passage from the region of active deep-water motion. 
Fig. 8. Observed salinity structure along the Bornholm Basin sections A and B shown in the map of Fig. 1. (i) 19 July 1986, (ii) 27 July 1986, (iii) 29 July 1986 and (iv) 31 July 1986.
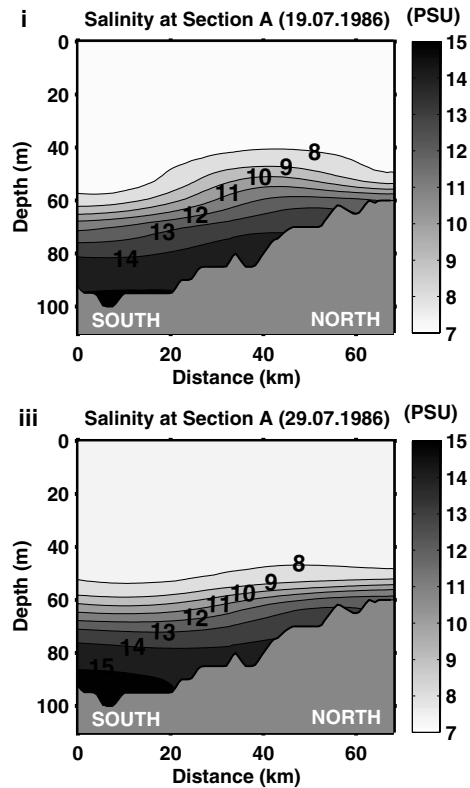
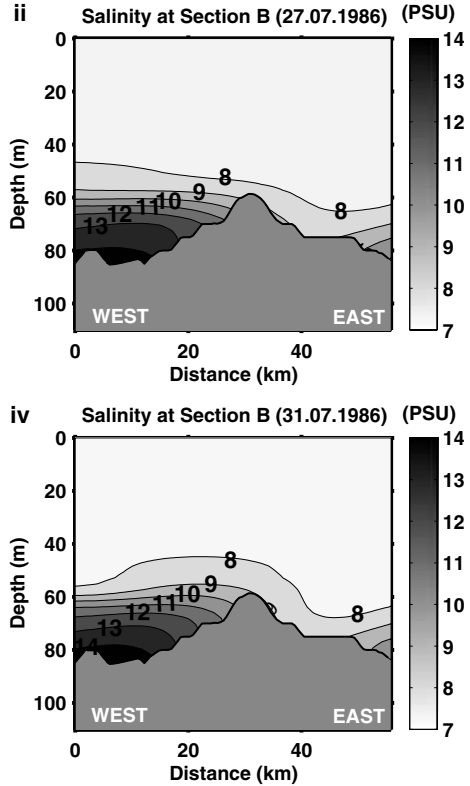

separating-streamline location (cf. Appendix A), where the maximal-transport estimate turned out to be $63700 \mathrm{~m}^{3} \mathrm{~s}^{-1}$, that is, approximately the result previously obtained when applying the Whitehead et al. (1974) formula.

It is thus recognized that in all cases dealt with here the hydraulic maximal-transport calculations based on the long-term climatology of the Bornholm and Gdansk Basins show considerable disagreement with the observed deep-water overflow through the Stolpe Channel. It is not immediately evident if this is due to the flow being submaximal, to an 'inadvertent' choice of density difference $\Delta \rho$ and upstream interface height $\eta_{\infty}$, or whether the applicability of the hydraulic approach is limited by more inherent features of the system such as a pronounced sensitivity to wind forcing and friction. As an attempt to resolve these questions we next examine some oceanographic field measurements from the area.

\section{Field observations}

Conceivably the average properties of the long-term records from the interior of the two basins connected by the Stolpe Channel could be unrepresentative as regards the dynamics of the deepwater overflow. Thus we shall here present and discuss some results from the field investigations conducted by the Finnish Institute of Marine Research in the 1980s. The most comprehensive hydrographic surveys were undertaken in 1986, and we thus focus on this data set from which some important CTDsections are shown in the map of Fig. 1. Transect A spans the greater part of the Bornholm Basin, longitudinal section B originates in this upstream reservoir and extends well into the Stolpe Channel, where cross-section $\mathrm{C}$ is located somewhat east of the sill.
The first surveys were carried out July 19-27, 1986 and the salinity structure along sections A and B is shown in Figs. $8 \mathrm{i}$ and ii. A dome-like feature across the northern part of the Bornholm Basin is clearly visible, its presence further corroborated by other FIMR hydrographic observations not reported here. Transect B from the upstream reservoir into the Stolpe Channel shows how efficiently the threshold serves as an impediment for the unrestricted flow of the densest deep water, only permitting a limited transport of intermediately saline water through the Stolpe Channel. When these two sections were revisited July 29-31, cf. Figs. 8 iii and iv, the deep-water dome was no longer in evidence.

Of the three transects which were worked across the sill region of Stolpe Channel (section C), that obtained on July 26 has already been reported in Fig. 2; the two others (July 30 and August 2) are shown in Fig. 9. Assuming that the deep-water flow was in geostrophic balance, the average baroclinic velocities below the 7.9 isohaline could be determined. This yielded deep-water fluxes of 10500,3700 and $19600 \mathrm{~m}^{3} \mathrm{~s}^{-1}$ on July 26, 30, and August 2 , respectively. These transport estimates, as well as the hydrographic observations, indicate that the overflow cannot be regarded as stationary, contrary to what tacitly has been assumed when pursuing the 'climatological' approach of Section 2.

The observational results are not least of interest since they offer the possibility of refining the parameter estimates in Section 2 underlying the hydraulic maximal-transport calculations presented above. We thus first note that a set of FIMR currentmeter records from the campaign in July/August 1986 does not overtly contradict the assumption that the upstream-reservoir transport has the character of a left-bank boundary current (a state of affairs with considerable implications for the manner in which the hydraulic analysis is conducted, cf. the Appendix). Fig. 10 thus shows these results from the region adjacent to the Stolpe 


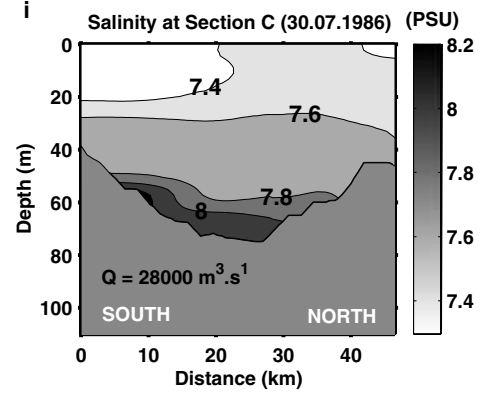

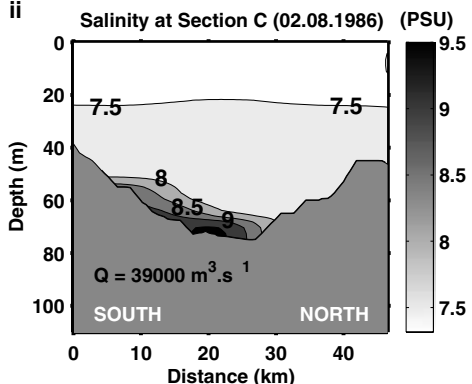

Fig. 9. Salinity sections across the Stolpe Channel threshold area (section C in Fig. 1). (i) 30 July 1986 and (ii) 2 August 1986.

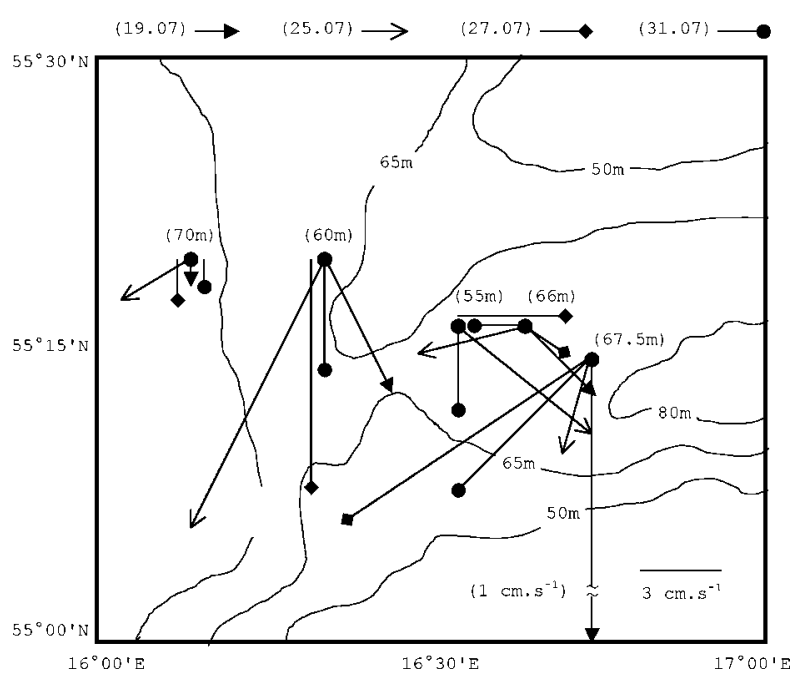

Fig. 10. Deep-water motion in the Stolpe Channel threshold region during the latter part of July 1986 as estimated from RCM arrays deployed by FIMR. Barotropic surface-layer motion has been eliminated from these deep-water RCM records at the observational depths shown within parentheses in the graph.

Channel threshold, where the barotropic surface-layer flow has been eliminated from the RCM records at deeper levels. In this context it should also be underlined that the presence of a deepwater boundary current along the northern rim of the Bornholm Basin is consonant with the outcome of the comprehensive surveys conducted by Piechura and Beszczyńska-Möller (2003).

An interesting phenomenon, allowance for which should be made in the hydraulic calculations, becomes evident when the hydrographic results from transect B across the Bornholm basin (Fig. 8) are judged in relation to the sections across the StolpeChannel threshold (Figs. 2, 9). From these three latter diagrams it is recognized that in no case does water of salinities above 13 cross the sill, a situation which raises the possibility of prescribing the level of this isohaline as an upstream-reservoir 'false bottom'. This methodology, which reduces the potential depth $D_{\infty}$ compared to the case considered in Section 3, has already been successfully employed elsewhere in the Baltic; cf. Laanearu et al. (2000). Using the hydrographic observations it is also possible to estimate the resulting $\mathrm{g}^{\prime}$-values when water masses of salinities above 13 are excluded from the calculations. A reasonable range of reduced gravities was found to span the interval $1.96-3.92 \times 10^{-2} \mathrm{~ms}^{-2}$ centred on the climatological mean determined in Section 2.

On the basis of these values a sensitivity study of the deepwater maximal-transport characteristics of the Stolpe Channel has been undertaken for a 'false bottom' depth, $D_{\infty}$, varying between 25 and $35 \mathrm{~m}$ and the reduced gravity g' assuming values within the above-mentioned interval. The deep-water is, as previously, defined as having salinities above 7.9 and the upstreamreservoir level of this separating isohaline is, for the purposes of this sensitivity study, retained at the climatological value $\eta_{\infty}=$ $23 \mathrm{~m}$. The outcome of the analyses, carried through using the method presented in the Appendix, is summarized in Fig. 11. Here the results are normalized with respect to the maximal transports for $D_{\infty}=30 \mathrm{~m}$, viz. $42400 \mathrm{~m}^{3} \mathrm{~s}^{-1}$ for $\mathrm{g}^{\prime}=1.96$ $\times 10^{-2} \mathrm{~m} \mathrm{~s}^{-2}, 62800 \mathrm{~m}^{3} \mathrm{~s}^{-1}$ for $\mathrm{g}^{\prime}=2.94 \times 10^{-2} \mathrm{~m} \mathrm{~s}^{-2}$, and $82800 \mathrm{~m}^{3} \mathrm{~s}^{-1}$ for $\mathrm{g}^{\prime}=3.92 \mathrm{~m} \mathrm{~s}^{-2}$. This wide range of scaling factors shows how strongly the deep-water overflow is affected by the gravitational forcing, that is, the density difference between the upper and lower layers. As recognized from the diagram, this is in marked contrast to the dependence upon the prescribed upstream-reservoir potential vorticity as mirrored by $D_{\infty}$, for which quantity the maximal transports prove to be comparatively insensitive.

\section{Discussion}

The results reported above from the FIMR field survey in July/August 1986 highlight a number of important questions with bearing on how useful it is to apply hydraulic theory for estimating the deep-water transport capacity of the Stolpe Channel. It is, for example, striking to which extent the geostrophically estimated transports from the cross-channel hydrographic sections (Figs. 2 and 9) deviate not only from one another, but also from theoretical estimates. With the caveat that the flow may be submaximal, it must be kept in mind when judging these discrepancies that $1 \frac{1}{2}$-layer hydraulic theory pertains to highly idealized conditions, none of which are fully satisfied in the southern Baltic. The stationarity condition only poses minor problems in this regard, since the deep-water flows under consideration here are characterized by changes over 
Fig. 11. Deep-water maximal-transport results for the Stolpe Channel for $\mathrm{g}^{\prime}=1.96$, 2.94 and $3.92 \times 10^{-2} \mathrm{~m} \mathrm{~s}^{-2}$, respectively. The results, normalized using the maximal transport for $D_{\infty}=30 \mathrm{~m}$, are shown for $D_{\infty}$ ranging from 25 to $35 \mathrm{~m}$. Return flow has been replaced by a stagnant zone.

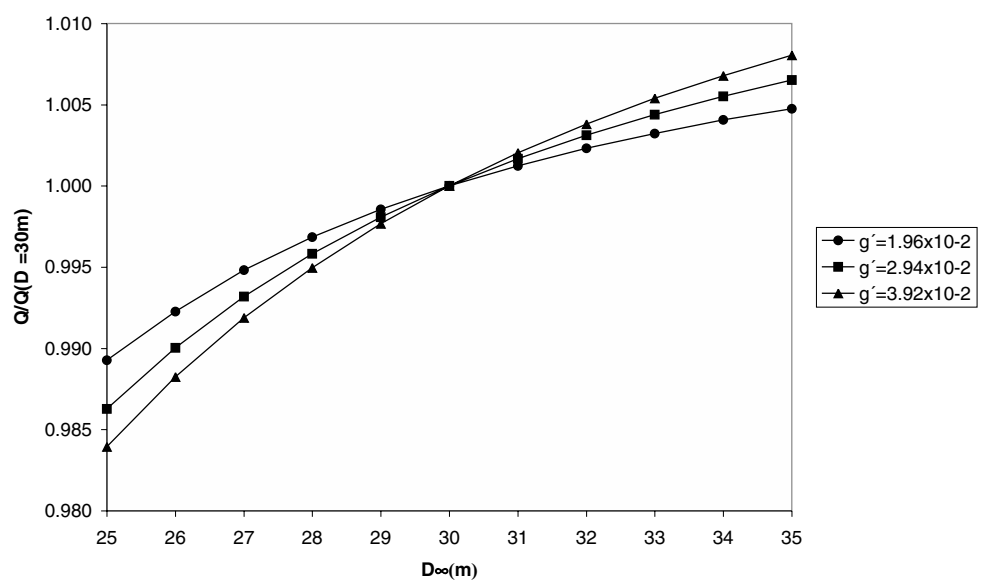

timescales well exceeding the inertial period. A more serious constraint is the requirement of a deep as well as passive upper layer, conditions which cannot be regarded as fulfilled, cf. the hydrographic observations in Figs. 2, 8 and 9 as well as the results presented by Piechura and BeszczyńskaMöller (2003). A numerical study (Lehmann and Hinrichsen, 2000) furthermore indicates that, on average, the transports of heat and salt through the Stolpe Channel are due to currents mainly driven by the surface stress. Krauss and Brügge (1991) had previously shown that even quite moderate $\left(\sim 8 \mathrm{~m} \mathrm{~s}^{-1}\right)$ easterly and northerly winds over the southern Baltic were capable of generating a deep-water flow of around $30000 \mathrm{~m}^{3}$ $\mathrm{s}^{-1}$ from the Bornholm to the Gdansk Basin. Another serious issue is whether the Stolpe Channel deep-water flow fulfills the criterion of being close to inviscid. Bottom and interfacial frictional effects acting on the entire deep-water column are significant due to the comparative shallowness of the lower layer; cf. the well-documented entrainment taking place after the high-saline water masses have debouched from the Kattegat through the Danish straits (Pedersen, 1977). These effects are of such magnitude that it appears likely we are not only dealing with minor frictional modification of hydraulic flow of the type investigated by Pratt (1986), but rather with the more fundamental question whether the dynamics of the flow in fact are dominated by inertial effects as required within a hydraulic framework.

A partial answer to this latter query can be obtained by applying the same type of frictional considerations to the Stolpe Channel deep-water flow as used by Lundberg (1983) when dealing with conditions in the Bornholm Channel. From Figs. 1, 3 and 4 it can be deduced that the climatological along-channel slope of the 7.9 isohaline (used as an idealized interface) between hydrographic stations BY5 and BCS III-10 in the Bornholm and Gdansk Basins, respectively, is around $1.5 \times 10^{-4}$ (i.e. roughly the same as encountered in the Bornholm Channel). The resulting pressure gradient is associated with an interior geostrophic cross-channel flow, which under stationary conditions must be compensated for by Ekman-layer transports along the bottom and the interface. These are partially forced by an interior alongchannel geostrophic flow, which thus can be determined from the requirement of continuity of the cross-channel mass fluxes over each vertical across the passage. From the results due to Knudsen (1900) as well as Meier and Kauker (2003) it is furthermore recognized that the long-term average upper-layer velocities in the Stolpe-Channel region are of a magnitude less than $1 \mathrm{~cm} \mathrm{~s}^{-1}$ and hence negligible in the present context. Making use of the previously introduced parabolic Stolpe-Channel bathymetry, the mathematical problem (Lundberg, 1983) becomes analytically tractable. Under the assumption that the vertical exchange coefficients in the Bornholm and Stolpe Channels are the same, a series of diagnostic calculations based on the previously outlined climatology yielded the results shown in Fig. 12.

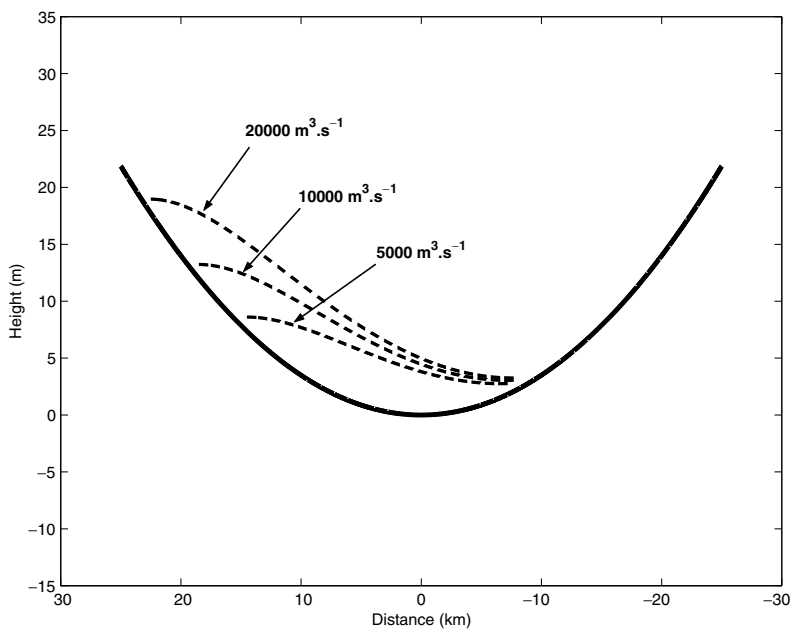

Fig. 12. For a frictionally balanced flow, this diagram shows the cross-channel behaviour of the idealized interface (corresponding to the 7.9 isohaline). The realizations represent deep-water transports of approximately 5000, 10000 and $20000 \mathrm{~m}^{3} \mathrm{~s}^{-1}$. Calculations based on the parabolic geometry shown in Fig. 6. 
This diagram shows the predicted cross-channel configuration of the idealized interface (identified with the 7.9 isohaline) for deep-water transports of 5000, 10000 and $20000 \mathrm{~m}^{3} \mathrm{~s}^{-1}$ when it is assumed that the flow is frictionally balanced according to the considerations above. As seen from a comparison with the hydrographic results in Figs. 2 and 9, the location of these calculated interfaces is consonant with the field observations, although it is not a priori given that average climatological conditions held sway in July and August 1987. It has thus been concluded that direct observations of the hydrographic conditions at the sill and in the Bornholm and Gdansk basins do not suffice for deciding whether the deep-water flow through the Stolpe Channel predominantly is governed by frictional or inertial effects. This question is further complicated by the possibility of the latter type of flow being submaximal.

For oceanic deep-water flows hydraulic theory is known to serve a useful purpose (Whitehead, 1998). In the geographically limited and rather shallow southern Baltic it is questionable whether a hydraulic framework is useful when dealing with the deep-water flow through the Stolpe Channel. It should particularly be noted that Krauss and Brügge (1991) showed that southerly and westerly winds can give rise to a westerly-directed deep-water transport through the passage, viz. a flow reversal in terms of the long-term hydrographic conditions characterizing the Bornholm and Gdansk Basins, cf. Section 2. However, during periods of major deep-water inflows to the Baltic (Schinke and Matthäus, 1998), reservoirs such as the Arkona and Bornholm basins are characterized by large and comparatively steady pools of deep water, and at these times the use of hydraulic theory can be justified, cf. Laanearu and Lundberg (2000). On these occasions the transports may well approach the upper bounds obtained from hydraulic theory. At other times, when the deepwater inflow from the Kattegat is weaker, frictional effects as well as the modulation of the flow caused by wind forcing (Krauss and Brügge, 1991) most likely invalidate the hydraulic approach. This longer-term non-stationarity, incidentally, highlights why the results due to Pratt (1997) may not be directly applicable for describing how the deep-water basins of the southern Baltic are drained.

To conclude this study it deserves mention that hydraulic theory has proved to be a useful tool in other regions of the Baltic. Hence it proved possible to estimate the Irbe Strait 'deep-water' inflow to the Gulf of Riga on a hydraulic basis by regarding the intermediate water masses in the western Gotland Basin as a large and steady upstream reservoir, and using the Baltic main halocline as a false bottom, cf. Laanearu et al. (2000). Another region where $1 \frac{1}{2}$-layer hydraulic theory has proved suitable is the Aland Sea, where the deep-water inflow to the Bothnian Sea takes place through the narrow Understen-Märket passage with a threshold depth of around $90 \mathrm{~m}$. The Alland Sea is of a very limited geographical extent, and here the wind-driven surfacelayer circulation is much less pronounced than in the Southern Baltic.

\section{Acknowledgments}

The authors wish to acknowledge their debt of gratitude to Director-General Pentti Mälkki of the Finnish Institute of Marine Research for kindly making the field data from the R/V Aranda surveys available for the purposes of this study. Generous financial support from the International Meteorological Institute at Stockholm University facilitated the investigation. We furthermore thank an unknown reviewer for constructive comments on a previous version of the study.

\section{Appendix A: Hydraulic flow characteristics in the case of a stagnant zone}

The present analysis proceeds from that due to Nikolopoulos et al. (2003) by approximating the cross-sill bathymetry of the passage with a parabolic profile $\alpha x^{2}$, the coordinate system having its origin at the deepest point of the threshold. The interface $\eta(x)$ coincides with the left bank of the channel at $a$, and the stagnant region commences at $b$. Cross-channel velocities are much smaller than the along-channel velocity $v$, which is geostrophically balanced:

$v=\frac{g^{\prime}}{f} \frac{\partial \eta}{\partial x}$.

Cross-flow variations are much larger than those along-stream, and thus the potential vorticity may be approximated by

$P V=\frac{\left(f+\frac{\partial v}{\partial x}\right)}{D}=\frac{d B}{d \psi}$.

Here $D(x)$ is the lower-layer depth and $\psi$ is the transport streamfunction defined by $D v=\partial \psi / \partial x, D v=-\partial \psi / \partial y, \psi(a)=$ $-Q / 2$ and $\psi(b)=Q / 2$, where $Q$ represents the deep-water transport and the Bernoulli function $B(\psi)$ the total energy.

The deep water originates from a source region of finite depth $D_{\infty}$, implying a non-zero potential vorticity. Eqs. (A1) and (A2) yield a differential equation for $\eta$ :

$\frac{\partial^{2} \eta}{\partial x^{2}}-\frac{1}{\lambda^{2}} \eta+\frac{1}{\lambda^{2}}\left(D_{\infty}+\alpha x^{2}\right)=0$,

where $\lambda=\left(g^{\prime} D_{\infty}\right)^{1 / 2} / f$ is the internal Rossby radius of deformation based on the upstream-reservoir depth. Since we limit ourselves to examining an overall flow in the positive $y$-direction, appropriate boundary conditions (Nikolopoulos et al., 2003) are $\eta(a)=\alpha a^{2}, \eta(b)=\eta_{\infty}$, and $\partial \eta / \partial x(b)=0$. The conditions at $x=b$ are consonant with the Bernoulli equation, which, in the standard case of an upstream reservoir with a quiescent interior and a left-bank boundary current (Gill 1976), assumes the form

$B(\psi)=\frac{1}{2} v^{2}+g \prime \eta=f\left(\psi-\frac{Q}{2}\right)+g / \eta_{\infty}$,

where $\eta_{\infty}\left(<D_{\infty}\right)$ is the upstream-reservoir interface height above the sill. At the streamline delimiting the stagnant zone the 
interface level is taken to coincide with $\eta_{\infty}$, yielding an alongchannel velocity equal to zero (which precludes vortex-sheet instability).

Applying these three conditions to the general solution of Eq. (A3) ultimately yields an expression for $\eta(x)$ in closed form as well as an explicit relationship between $a$ and $b$, here given in nondimensional 'hatted' form:
Knudsen, M. 1900. Ein hydrographischer Lehrsatz. Ann. der Hydrographie und Maritimen Met. 28, 316-320.

Kõuts, T. and Omstedt, A. 1993. Deep water exchange in the Baltic proper. Tellus 45A, 311-324.

Krauss, W. and Brügge, B. 1991. Wind-produced water exchange between the deep basins of the Baltic Sea. J. Phys. Oceanogr. 21, 373384 .

$$
\hat{a}=\hat{b}+\ln \left[\frac{\left\{-(2 / r+1) \pm\left[4 \eta_{\infty} /\left(r D_{\infty}\right)+2\left(\eta_{\infty} / D_{\infty}-\hat{b}^{2} / r\right)-\left(\eta_{\infty} / D_{\infty}-\hat{b}^{2} / r\right)^{2}\right]^{1 / 2}\right\}}{\left\{\left(\eta_{\infty} / D_{\infty}-\hat{b}^{2} / r\right)-(2 / r+1)-2 \hat{b} / r\right\}}\right] .
$$

In this expression a horizontal and vertical rescaling on the basis of $\lambda$ and $\alpha \lambda^{2}$, respectively, has been undertaken and the non-dimensional parameter $r=f^{2} / g^{\prime} \alpha$ has been introduced, cf. Borenäs and Lundberg (1986).

Examining Eq. (A5) in the limit $\eta_{\infty} / D_{\infty}-\hat{b}^{2} / r \rightarrow 0$, that is, when the separating streamline impinges upon the bank of the passage, it is recognized that the minus sign in the numerator represents a spurious solution branch yielding the degenerate result $a=b$. The remaining branch of Eq. (A5), however, represents a consistent solution since both numerator and denominator are negative definite. The criterion that the discriminant always be non-negative ultimately yields a general constraint for the nondimensionalized lower-layer depth at the separating streamline:

$\eta_{\infty} / D_{\infty}-\hat{b}^{2} / r<1+\left[1+4 \eta_{\infty} /\left(r D_{\infty}\right)\right]^{1 / 2}$.

The deep-water transport is obtained from the Bernoulli equation (A4) evaluated at $x=a$, that is, the left bank:

$$
Q=D_{\infty}\left[g^{\prime} \eta_{\infty}-v(a)^{2} / 2-g^{\prime} \eta(a)\right] / f,
$$

where $v(a)$ is determined from Eq. (A1). By hereafter applying Eq. (A5), the transport $Q$ can be maximized with respect to $b$.

Imposing the stagnant-zone condition, to ensure a unidirectional flow through the channel, is thus seen to considerably simplify the formal mathematical procedure compared to that required to resolve the wholly implicit standard problem previously dealt with by Borenäs and Lundberg (1986).

\section{References}

Borenäs, K. and Lundberg, P. 1986. Rotating hydraulics of flow in a parabolic channel. J. Fluid Mech. 167, 309-326.

Borenäs, K. and Lundberg, P. 1988. On the deep-water flow through the Faroe Bank Channel. J. Geophys. Res. 93C, 1281-1292.

Borenäs, K. and Pratt, L. 1994. On the use of rotating hydraulic models. J. Phys. Oceanogr. 24, 108-123.

Borenäs, K. and Nikolopoulos, A. 2000. Theoretical calculations based on real topography of the maximal deep-water flow through the Jungfern Passage. J. Mar. Res., 58, 709-719.

Gidhagen, L. and Håkansson, B. 1992. A model of the deep water flow into the Baltic Sea. Tellus 44A, 414-424.

Killworth, P. 1994. On reduced-gravity flows through sills. Geophys. Astrophys. Fluid Dyn. 75, 91-106.
Laanearu, J. and Lundberg, P. 2000. Topographic control of rotating deep water flow through the combination of a sill and a horizontal constriction. J. Geophys. Res. 105C, 28663-28669.

Laanearu, J., Lips, U. and Lundberg, P. 2000. On the application of hydraulic theory to the deep-water flow through the Irbe Strait. $J$. Mar. Syst. 25, 323-332.

Lehmann, A. and Hinrichsen, H.-H. 2000. On the thermohaline variability of the Baltic Sea. J. Mar. Syst. 25, 333-357.

Liljebladh, B. and Stigebrandt, A. 1996. Observations of the deepwater flow into the Baltic Sea. J. Geophys. Res. 101C, 88958911.

Lundberg, P. 1983. On the mechanics of the deep-water flow in the Bornholm Channel. Tellus 35A, 149-158.

Mälkki, P. 1988. Hydrography in and overflow from the Bornholm Basin of the Baltic Sea in Autumn. IAPSO, Procés-verbaux No. 17, International Union of Geodesy and Geophysics. XIX General Assembly at Vancouver, Del Mar, California, p. 188.

Meier, M. and Kauker, F. 2003. Modelling decadal variability of the Baltic Sea: 2. Role of freshwater inflow and large-scale atmospheric circulation for salinity. J. Geophys. Res. 108C, 2866328669.

Meier, H. E. M., Döscher, R. and Faxen, T. 2003. A multiprocessor coupled ice-ocean model for the Baltic Sea: Application to salt inflow. J. Geophys. Res. 108(C8), 3273, doi:10.1029/2000JC000521.

Nikolopoulos, A., Borenäs, K., Hietala, R. and Lundberg, P. 2003. Hydraulic Estimates of the Denmark Strait Overflow. J. Geophys. Res. 108(C3), 3095, doi:10.1029/2001JC001283.

Omstedt, A., Mueller, L. and Nyberg, L. 1997. Interannual, seasonal and regional variations of precipitation and evaporation over the Baltic Sea. Ambio 26, 484-492.

Pedersen, F. 1977. On dense bottom currents in the Baltic deep water. Nordic Hydrol 8, 297-316.

Petrén, O. and Walin, G. 1976. Some observations of the deep flow in the Bornholm strait during the period June 1973-December 1974. Tellus 28, 74-87.

Piechura, J. and Beszczyńska-Möller, A. 2003. Inflow waters in the deep regions of the southern Baltic Sea - transport and transformations. Oceanologia 45, 593-621.

Pratt, L. J. 1986. Hydraulic control of sill flow with bottom friction. J. Phys. Oceanogr. 16, 1970-1980.

Pratt, L., 1997. Hydraulically drained flows in rotating basins. Part II: Steady flow. J. Phys. Oceanogr. 27, 2522-2535.

Pratt, L. and Lundberg, P. 1991. Hydraulics of rotating strait and sill flows. Ann. Rev. Fluid Mech. 23, 81-106. 
Rydberg, L. 1980. Rotating hydraulics in deep-water channel flow. Tellus 32, 77-89.

Schinke, H. and Matthäus, W. 1998. On the causes of major Baltic inflows - an analysis of long time series. Cont. Shelf Res. 18, 6797.

Whitehead, J. A. 1989. Internal hydraulic control in rotating fluids - applications to oceans. Geophys. Astrophys. Fluid Dyn. 48, 169192.

Whitehead, J. A. 1998. Topographic control of oceanic flows in deep passages and straits. Rev. Geophys. 36, 423-440.

Whitehead, J., Leetma, A. and Knox, R. 1974. Rotating hydraulics of strait and sill flows. Geophys. Fluid Dyn. 6, 101-125. 